\title{
Práticas educativas na promoção da alimentação adequada e saudável para as pessoas com doença falciforme
}

\section{Description of the educational practices developed while promoting an adequate and healthy diet for people with sickle cell disease}

\author{
Isabel Nascimento dos Santos' \\ Jorginete de Jesus Damião Trevisani' \\ Marta Citelli dos Reis? \\ Pilar Silva Raphael Mataratzis \\ Karen Cordovil \\ Ana Cecilia Freitas' \\ Débora Lemos Lino' \\ Juliana Omena \\ Cláudia dos Santos Cople-Rodrigues' \\ ${ }^{1}$ Centro de Referência de Nutrição à Pessoa \\ com Doença Falciforme (NUTRIFAL), Instituto \\ de Nutrição. Universidade do Estado do Rio de \\ Janeiro. Rio de Janeiro, RJ, Brasil.
}

Correspondência / Correspondence Isabel Nascimento dos Santos E-mail: isabel.nutri@yahoo.com.br

\section{Resumo}

A doença falciforme (DF) é uma doença crônica, hereditária, caracterizada pela presença da hemoglobina S, que leva inúmeras complicações clínicas e necessidades alimentares especiais. $\mathrm{O}$ objetivo deste artigo é descrever as ações de educação alimentar e nutricional para pessoas com DF. Trata-se de um relato de experiência de práticas educativas, realizadas no ambulatório de hematologia de um hospital universitário, por um centro de referência, entre os anos de 2010 e 2012. Os dados foram obtidos a partir dos relatórios das práticas educativas. No total, 171 pessoas participaram de 15 práticas. Os assuntos abordados foram agrupados em quatro temas principais: Recomendações gerais para as pessoas com a DF; Aumento dos requerimentos de nutrientes; Estratégias para a diminuição do consumo de sal e sódio; e Biodisponibilidade de ferro nos alimentos. As práticas educativas permitiram promover reflexões e orientações sobre práticas alimentares mais adequadas e a identificar, a partir das falas das pessoas, dúvidas sobre as recomendações alimentares na DF. O espaço da sala de espera permitiu a troca de conhecimentos entre os profissionais que conduziram as práticas e os participantes. Contudo, observou-se como pontos negativos o foco centrado nos nutrientes, a dificuldade de adoção de estratégias metodológicas mais direcionadas para a idade e a falta de inserção de equipe multiprofissional. A experiência apresentada traz reflexões importantes sobre a necessidade de a educação alimentar e nutricional ser ferramenta comum aos profissionais de saúde, em toda a rede de assistência às pessoas com a doença falciforme.

Palavras-chave: Hemoglobina. Doença Falciforme. Educação Alimentar e Nutricional. Exigências Nutricionais. Consumo de Alimento. Promoção da Saúde. 


\section{Abstract}

Sickle Cell Disease (SCD) is a chronic inherited disorder, characterized by the presence of abnormal erythrocytes containing $\mathrm{S}$ hemoglobin ( $\mathrm{HbS}$ ) that leads to diverse clinical complications and special nutritional needs. This article aimed to describe food and nutrition education actions for people with $\mathrm{SCD}$. This is a report of the experience with educational practices developed by a Reference Center and performed at a hematology ambulatory in the university hospital from 2010 to 2012 that aimed to promote adequate and healthy eating habits. Data were obtained by consulting the educational practice notes; 171 people participated in 15 educational practices. The subjects were grouped into four main themes: General recommendations for people with sickle cell disease; Increased nutrient requirements; Strategies to reduce salt and sodium intake; and Iron content and availability in foods. Educational practices allowed for the reflection and guidance on appropriate feeding practices and for the findingof doubts on dietary recommendationsfor SCD through people's own reports. The space in the waiting room promoted the exchange of knowledge between the professionals who conducted the practices and participants. However, it was noted as weaknesses, the focus centered on the nutrients, the difficulty of adopting methodological strategies more targeted for age and the lack of inclusion of a multidisciplinary team. The experience presented has important reflections on the need for food, and food and nutrition education is common tool to healthcare professionals throughout the network of assistance to people with sickle cell disease.

Key words: Hemoglobin. Sickle Cell Disease. Food and Nutrition Education. Nutritional Requirements. Food Consumption. Health Promotion.

\section{Introdução}

Originária da África, a doença falciforme (DF) é uma doença crônica, causada pela mutação no gene da hemoglobina beta, que altera a estrutura da hemoglobina $\mathrm{A}(\mathrm{HbA})$, resultando na formação da hemoglobina $\mathrm{S}(\mathrm{HbS}) \cdot{ }^{1,2}$

A presença da $\mathrm{HbS}$ gera inúmeras alterações patológicas nas hemácias, que levam a vaso-oclusão e hiper-hemólise. ${ }^{3-5}$ Esses eventos proporcionam o aparecimento de complicações secundárias, como 
hipertensão arterial, derrame pulmonar, insuficiência renal, insuficiência cardíaca congestiva, úlceras de perna, osteonecrose da cabeça do fêmur e úmero, entre outras. ${ }^{1}$

As manifestações clínicas e as complicações secundárias à DF impactam principalmente na qualidade e na expectativa de vida, sendo comum a morte prematura ${ }^{6-8} \mathrm{Com}$ vistas à prevenção ou minimização destas intercorrências, devem ser implementadas ações de promoção da saúde, a fim de reduzir sua morbimortalidade. Isso é importante, pois não existe até hoje um tratamento completamente eficaz e inócuo para as pessoas com DF. Para tanto, é preciso que esta doença seja reconhecida como um problema de saúde pública e que a assistência às pessoas com DF seja efetiva em todos os níveis de complexidade no Sistema Único de Saúde (SUS). ${ }^{9}$

Um dos aspectos essenciais que deve ser priorizado na assistência às pessoas com DF são os cuidados relativos à alimentação e nutrição, pois estão associados ao melhor prognóstico da doença, uma vez que em função das complicações clínicas, este grupo apresenta necessidades alimentares especiais, devido ao aumento das demandas de líquidos, ${ }^{10,11}$ de energia, ${ }^{12,13}$ de vitaminas (ácido fólico, vitamina D) e de minerais (cálcio, zinco, magnésio). ${ }^{14,15}$ Além disso, uma parcela de pessoas com a DF, as que recebem sucessivas transfusões sanguíneas, pode apresentar o quadro de sobrecarga de ferro corporal, ${ }^{16}$ requerendo maior cuidado em relação ao consumo de alimentos fontes deste micronutriente.

As características socioeconômicas e culturais neste grupo também estão associadas à má nutrição, visto que a doença pode impactar de forma negativa na situação econômica individual e familiar, ou agravá-la em função da sua presença, e que este grupo frequentemente se encontra em situação de vulnerabilidade social, pois as maiores prevalências da DF estão na população negra (constituída por pretos e pardos). ${ }^{17}$

Sabe-se que, no Brasil, a população negra convive com as piores condições de vida, baixa escolaridade, remuneração insuficiente, condições sanitárias inadequadas e dificuldades em prover suas necessidades básicas. ${ }^{18,19}$ As desigualdades econômicas, de gênero e étnicas, bem como o acesso diferenciado aos bens e serviços públicos, são fatores determinantes da Insegurança Alimentar (IA), ${ }^{20}$ que neste grupo se soma à vulnerabilidade biológica, num ciclo contínuo e inter-relacionado de determinantes desfavoráveis para a Segurança Alimentar e Nutricional (SAN).

As diferentes pesquisas de abrangência nacional que avaliaram a SAN nos domicílios brasileiros demostram que as situações de Insegurança Alimentar (IA) estão fortemente relacionadas à população negra. A Pesquisa Nacional de Amostra do Domicílio (PNAD), de 2004 e 2009, e a Pesquisa Nacional de Demografia da Saúde da Mulher e da Criança (PNDS), em 2006, avaliaram diretamente a situação de segurança alimentar no Brasil. Considerando o fator cor/raça em 2004 (PNAD), viviam em situação de (IA) grave 11,5\% da população negra. ${ }^{21}$ Em 2006 (PNDS), observou- 
se que a prevalência de IA grave nas mulheres de cor autodeclarada negra era duas vezes e meia maior $(6,5 \%)$ se comparadas às mulheres de cor branca $(2,7 \%) .{ }^{22}$ Por fim, no último estudo de âmbito nacional, PNAD 2009, 43,4\% dos brasileiros pretos ou pardos estavam em situação de IA. ${ }^{21}$

O consumo da alimentação adequada pode ainda ser prejudicado durante as crises álgicas, frequentemente associadas à inapetência, ao aumento das demandas nutricionais e à ingestão inadequada dos alimentos ricos em vitaminas e minerais antioxidantes. ${ }^{23}$

As pessoas com necessidades alimentares especiais carecem de acesso e de informação sobre os alimentos adequados, com vistas ao fortalecimento do exercício da autonomia, do cuidado compartilhado e da garantia do direito humano à alimentação adequada e saudável. ${ }^{24}$ Nesta direção, foi proposto um projeto de extensão que consistia na implementação de atividades educativas num ambulatório de hematologia, tendo em vista o estímulo à Promoção da Alimentação Adequada e Saudável (PAAS). Assim, o presente trabalho tem por objetivo descrever as ações de Educação Alimentar e Nutricional (EAN) desenvolvidas para pessoas com doença falciforme.

\section{Metodologia}

Trata-se de um relato de experiência de práticas educativas com foco na promoção da alimentação adequada e saudável, voltadas para as pessoas com DF, por meio de grupos de sala de espera.

Estas práticas educativas integravam as atividades do Centro de Referência de Nutrição à Pessoa com Doença Falciforme (NUTRIFAL). O Centro é uma parceria entre o Instituto de Nutrição da Universidade do Estado do Rio de Janeiro (INU/UERJ) e o Ministério da Saúde (MS), e tem o objetivo de produzir conhecimento e subsidiar políticas públicas, na área de alimentação e nutrição, para as pessoas com doença falciforme, além de constituir-se como um espaço de educação continuada aos profissionais que atuam nas redes estadual e municipais de saúde, no âmbito do estado do Rio de Janeiro.

As práticas foram realizadas na recepção do ambulatório de hematologia do Hospital Universitário Pedro Ernesto (HUPE/UERJ) no período compreendido entre os anos de 2010 e 2012, sendo desenvolvidas por nutricionistas, professores e alunos de graduação em Nutrição.

Durante as práticas, registraram-se as falas dos participantes, os questionamentos, as respostas e a interação destes no desenrolar da atividade. Ao final, a equipe se reunia para discutir e refletir sobre o desenvolvimento da atividade, e analisar as impressões e a percepção da receptividade dos participantes frente aos assuntos apresentados. Um relatório era produzido, com o objetivo de consolidar as observações e reflexões para subsidiar as próximas atividades. 
A partir de 2011, passou a ser entregue aos participantes, no início de cada atividade, um questionário para autopreenchimento, com questões que avaliavam a atividade em relação ao tema apresentado e a abordagem utilizada, os quais poderiam ser avaliados como "bom", "regular" e "ruim".

Com o intuito de conhecer a população que compunha os grupos de sala de espera, foram elaborados e aplicados questionários de conhecimento prévio em quatro práticas. Os questionários eram aplicados anteriormente à realização da atividade e visavam identificar se os integrantes dos grupos da sala de espera eram usuários do serviço ou seus cuidadores, se havia uso de esquemas de terapias de transfusões, se o usuário fazia acompanhamento regular no serviço de saúde e ainda conhecer melhor o consumo alimentar.

O projeto de extensão foi aprovado pelo Departamento de Extensão da UERJ (no-4044) e pela Comissão de Ética do Hospital Universitário (número 2942/2011).

\section{Resultados}

No total, 171 pessoas participaram de 15 práticas educativas realizadas entre junho de 2010 e agosto de 2012, com duração máxima de 60 minutos. Em relação à composição dos grupos de sala de espera, os participantes eram usuários do serviço de hematologia ou seus cuidadores de diferentes faixas etárias. Vale ressaltar que, por se tratar de um espaço comum a todos os usuários do serviço, nos grupos de sala de espera também havia pessoas com outras doenças hematológicas.

Os assuntos abordados nas práticas educativas tinham como intuito promover a alimentação adequada e saudável das pessoas com DF, com a escolha de temas fundamentados nas especificidades nutricionais desta patologia. Os mesmos também foram escolhidos a partir da demanda dos participantes, que eram convidados a sugerir temas de seus interesses para serem discutidos nas práticas subsequentes.

As ações de PAAS foram fundamentadas em quatro temas principais: Recomendações gerais para as pessoas com a doença falciforme; Aumento dos requerimentos de nutrientes, como o ácido fólico, vitamina A, vitamina D e cálcio e nutrientes com ação antioxidante, necessidade hídrica e proteica; Estratégias para a diminuição do consumo de sal e sódio; e por fim, Biodisponibilidade e ferro nos alimentos. Os temas propostos, os referenciais teóricos que nortearam as ações, bem como as estratégias metodológicas utilizadas, encontram-se descritos no quadro 1. 
Quadro 1. Descrição das práticas educativas desenvolvidas na promoção da alimentação adequada e saudável para as pessoas com doença falciforme. Nutrifal, 2010-2012.

\begin{tabular}{|c|c|c|c|}
\hline & Tema & Referencial Teórico & Estratégia Metodológica \\
\hline \multirow{2}{*}{$\begin{array}{l}\text { Recomendações } \\
\text { Gerais para a } \\
\text { Alimentação } \\
\text { Adequada } \\
\text { na Doença } \\
\text { Falciforme }\end{array}$} & $\begin{array}{l}\text { Alimentação } \\
\text { adequada na } \\
\text { doença falciforme } \\
\text { Trabalhando } \\
\text { as escolhas dos } \\
\text { alimentos }\end{array}$ & $\begin{array}{l}\text { A alimentação } \\
\text { adequada é uma das } \\
\text { medidas preventivas } \\
\text { para minimizar as } \\
\text { manifestações clínicas e } \\
\text { secundárias à doença. }{ }^{1}\end{array}$ & $\begin{array}{l}\text { Apresentação e discussão } \\
\text { dos Dez Passos para a } \\
\text { Alimentação Saudável na } \\
\text { doença falciforme. } \\
\text { Dinâmica do self-service } \\
\text { com figuras de alimentos. }\end{array}$ \\
\hline & $\begin{array}{l}\text { Aproveitamento } \\
\text { integral dos } \\
\text { alimentos }\end{array}$ & $\begin{array}{l}\text { A alimentação integral } \\
\text { possui como princípio } \\
\text { básico a diversidade } \\
\text { de alimentos e a } \\
\text { complementação de } \\
\text { refeições, com o objetivo } \\
\text { de reduzir custo, } \\
\text { proporcionar preparo } \\
\text { rápido e oferecer paladar } \\
\text { regionalizado. } .^{25}\end{array}$ & $\begin{array}{l}\text { Tempestade de ideias: } \\
\text { benefícios do uso integral } \\
\text { dos alimentos, tipos de } \\
\text { alimentos usados e como } \\
\text { evitar o desperdício. }\end{array}$ \\
\hline \multirow[t]{3}{*}{$\begin{array}{l}\text { Aumento dos } \\
\text { Requerimentos } \\
\text { de Nutrientes } \\
\text { na Doença } \\
\text { Falciforme }\end{array}$} & $\begin{array}{l}\text { Consumo de } \\
\text { vegetais verde- } \\
\text { escuros } \\
\text { Alimentos verdes } \\
\text { ou amarelos }\end{array}$ & $\begin{array}{l}\text { Deficiência de ácido fólico } \\
\text { ocorre em resposta à } \\
\text { hemólise crônica. }{ }^{1}\end{array}$ & $\begin{array}{l}\text { Sorteio de nomes de } \\
\text { vegetais e discussão com } \\
\text { os participantes. } \\
\text { Exposição de gravuras } \\
\text { de alimentos verdes e } \\
\text { amarelos e discussão. }\end{array}$ \\
\hline & $\begin{array}{l}\text { Alimentos } \\
\text { antioxidantes }\end{array}$ & $\begin{array}{l}\text { Os níveis de antioxidantes } \\
\text { estão significativamente } \\
\text { diminuídos, incluído a } \\
\text { vitamina A. }{ }^{23,26}\end{array}$ & $\begin{array}{l}\text { Jogo da memória } \\
\text { com os alimentos que } \\
\text { contêm e não contêm os } \\
\text { antioxidantes. }\end{array}$ \\
\hline & $\begin{array}{l}\text { Nutrição e saúde } \\
\text { óssea }\end{array}$ & 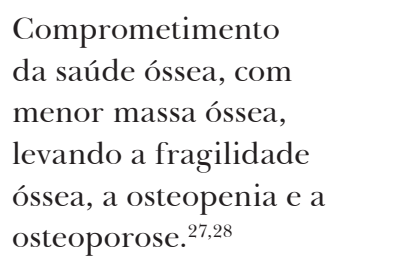 & $\begin{array}{l}\text { Análise sensorial de } \\
\text { vários tipos de leites e } \\
\text { discussão posterior a } \\
\text { experimentação. }\end{array}$ \\
\hline
\end{tabular}




\begin{tabular}{|c|c|c|c|}
\hline & Tema & Referencial Teórico & Estratégia Metodológica \\
\hline & Zinco e saúde & $\begin{array}{l}\text { É comum a deficiência } \\
\text { de zinco, principalmente } \\
\text { nas crianças, o que leva } \\
\text { ao retardo do crescimento } \\
\text { e diminuição da } \\
\text { imunidade. }{ }^{15}\end{array}$ & $\begin{array}{l}\text { Identificação e discussão } \\
\text { de gravuras de alimentos } \\
\text { ricos em zinco. }\end{array}$ \\
\hline & $\begin{array}{l}\text { Nutrientes e } \\
\text { imunidade } \\
\text { Alimentos e } \\
\text { defensa do corpo }\end{array}$ & $\begin{array}{l}\text { Maior propensão } \\
\text { às infecções e baixa } \\
\text { imunidade. }{ }^{29}\end{array}$ & $\begin{array}{l}\text { Jogo do Bingo: utilização } \\
\text { de cartelas com perguntas } \\
\text { sobre alimentos ou } \\
\text { nutrientes que estimulam } \\
\text { e ajudam na imunidade. } \\
\text { Jogo do Passa ou repassa: } \\
\text { Perguntas e respostas } \\
\text { sobre os alimentos que } \\
\text { melhoram a imunidade. }\end{array}$ \\
\hline & $\begin{array}{l}\text { Consumo de } \\
\text { água e líquidos }\end{array}$ & $\begin{array}{l}\text { A hidratação adequada } \\
\text { é uma medida de } \\
\text { prevenção contra a } \\
\text { hemoconcentração e } \\
\text { possível desidratação. }{ }^{1}\end{array}$ & $\begin{array}{l}\text { Analogia do consumo } \\
\text { diário de líquido/água e os } \\
\text { sinais de trânsito. }\end{array}$ \\
\hline & Leguminosas & $\begin{array}{l}\text { Aumento das necessidades } \\
\text { proteicas. }^{30}\end{array}$ & $\begin{array}{l}\text { Exposição e discussão de } \\
\text { diversas leguminosas secas }\end{array}$ \\
\hline $\begin{array}{l}\text { Consumo de sal } \\
\text { e sódio }\end{array}$ & $\begin{array}{l}\text { Condimentos } \\
\text { naturais }\end{array}$ & $\begin{array}{l}\text { Deve se evitar os alimentos } \\
\text { ricos em sódio, pois em } \\
\text { excesso pode aumentar } \\
\text { os níveis pressóricos e } \\
\text { favorecer a obstrução de } \\
\text { vasos sanguíneos. }{ }^{31}\end{array}$ & $\begin{array}{l}\text { Análise sensorial e } \\
\text { discussão de especiarias } \\
\text { naturais. }\end{array}$ \\
\hline $\begin{array}{l}\text { Ferro nos } \\
\text { alimentos }\end{array}$ & $\begin{array}{l}\text { Ferro nos } \\
\text { alimentos }\end{array}$ & $\begin{array}{l}\text { Os alimentos fontes de } \\
\text { ferro devem fazer parte } \\
\text { da alimentação cotidiana } \\
\text { das pessoas com DF, não } \\
\text { devendo ser excluído na } \\
\text { dieta. }^{32}\end{array}$ & $\begin{array}{l}\text { Exposição e discussão de } \\
\text { fotos de alimentos que } \\
\text { continham ferro do tipo } \\
\text { heme e não heme. }\end{array}$ \\
\hline
\end{tabular}


Para o primeiro tema, "Recomendações gerais para as pessoas com a doença falciforme", foram desenvolvidas três práticas educativas. Dada a necessidade de mobilizar as pessoas com DF para adesão a práticas alimentares adequadas, houve predomínio das práticas fundamentadas no aumento dos requerimentos de nutrientes na DF, com realização de nove atividades. Foram realizadas ainda duas práticas, uma para o tema "Estratégias para a diminuição do consumo de sal e sódio" e a outra sobre "Biodisponibilidade de ferro nos alimentos".

A partir de 2011, com a aplicação do questionário de avaliação, 11 práticas foram avaliadas, totalizando 98 participantes (57,3\%). As práticas educativas foram avaliadas positivamente. Apenas um participante avaliou como regular a proposta do tema "Biodisponibilidade de ferro nos alimentos" e duas pessoas como regular a estratégia metodológica utilizada na prática Jogo da Memória Antioxidante.

Com base nas observações da equipe, os adultos se envolviam mais quando na abordagem se utilizavam como recurso os alimentos in natura, para apresentação ou análise sensorial, o que ocorreu nas práticas “Que cheiro Que o Tempero tem?”; "O Quê Que o feijão tem?” e "Nutrição e Saúde Óssea". As crianças e os adolescentes tinham maior participação quando na abordagem se empregavam como estratégia metodológica os jogos lúdicos, o que ocorreu nas práticas "Jogo da Memória dos antioxidantes", "Bingo da Imunidade", "Self-service: Qual é sua escolha?”.

\section{Resultados dos Questionários de Conhecimento Prévio}

Os questionários de conhecimento prévio foram aplicados nas práticas" Ferro nos alimentos", "Trabalhando as escolhas dos alimentos", "Nutrição e Saúde Óssea" e "Zinco e Saúde”. Ao todo, foram respondidos 34 questionários, sendo 62\% usuários do serviço de hematologia e 38\% cuidadores.

Algumas questões foram dirigidas exclusivamente para os participantes com DF e seus cuidadores. Na prática educativa "Ferro nos Alimentos", os participantes foram questionados se já haviam sido orientados sobre o consumo de alimentos fontes de ferro na DF; sua importância na manutenção da saúde; as melhores fontes alimentares e o que fariam em situações de sobrecarga deste mineral. Dos nove respondentes, apenas três relataram ter recebido alguma orientação sobre o consumo de alimentos fontes de ferro. Dois participantes afirmaram:

Mais ou menos, falaram para diminuir alimentos ricos em ferro, parar de comer verduras. (P7)

Já, para comer bastante alimento que contenha ferro. (P8). 
Em relação às melhores fontes alimentares de ferro, os alimentos mais citados pelos participantes foram: em primeiro lugar, o feijão $(n=06 ; 75 \%)$; em segundo, as verduras $(n=5 ; 62,5 \%)$, seguidas pela carne vermelha, o fígado e a beterraba, cada um referido por $37,5 \%(\mathrm{n}=3)$ dos participantes.

Quando indagados o que deveriam fazer na situação de sobrecarga de ferro, cinco participantes $(55,5 \%)$ relataram que deixariam de comer os alimentos fontes de ferro; dois participantes reduziriam a quantidade $(22,2 \%)$ dos alimentos fontes e um participante fez o seguinte comentário: "Comer sorvete, milk-shake." (P3).

Na prática "Trabalhando as Escolhas Alimentares", os participantes foram convidados a refletir sobre sua alimentação, avaliando seus hábitos alimentares atribuindo pontos numa escala de zero a dez e, justificando sua pontuação. Quatro (44\%) dos nove participantes avaliaram como cinco a sua alimentação, porque comiam em horários irregulares e em pouca quantidade. Os demais participantes avaliaram como oito e meio, sete, nove e dez a sua alimentação; este último relatou que tinha uma alimentação saudável, pois consumia pouca quantidade de gordura e seguia todas as orientações do médico.

Na prática "Nutrição e Saúde Óssea”, os participantes foram questionados sobre os alimentos ricos em cálcio, vitamina $\mathrm{D}$ e vitamina $\mathrm{K}$, que são essenciais para a saúde óssea. Estes relataram como melhor alimento fonte destes nutrientes o ovo, citado por três de seis participantes (50\%). Quanto questionados especificamente a respeito do leite, os participantes relataram ingeri-lo, em sua maioria leite, com café ou com fruta.

Na prática "Zinco e Saúde", os participantes foram questionados se já tinham sido informados sobre o mineral zinco e se saberiam escolher seus alimentos fontes. Nove (90\%) entrevistados relataram desconhecê-lo; resultado igual foi obtido para as escolhas alimentares, onde apenas um participante afirmou saber identificar os alimentos fontes deste nutriente.

\section{Discussão}

Os principais objetivos da educação em saúde para doença falciforme são: permitir o apoderamento dos usuários sobre os cuidados necessários na DF, contribuindo para a formação de opinião favorável à saúde; possibilitar a tomada de decisões clínicas valorizando a saúde; promover o cuidado compartilhado; desmistificar a doença falciforme, difundindo seu conhecimento; fomentar processos de mudança social, econômica e cultural, para superar os problemas de saúde; e permitir o desenvolvimento da cidadania. ${ }^{33}$ 
As práticas educativas relatadas permitiram identificar dúvidas sobre recomendações alimentares na DF e, no escopo do alcance das estratégias utilizadas, promover reflexões e orientações sobre alimentação, visando contribuir para o exercício da autonomia e do apoderamento destas pessoas sobre sua saúde. Isto foi facilitado pelo fato de que as atividades educativas realizadas tiveram por base o diálogo. Segundo Paulo Freire (1996), é através do diálogo que os pensamentos existentes vão mudando e novos conhecimentos são criados. ${ }^{34} \mathrm{O}$ espaço da sala de espera também permitiu a troca de conhecimentos entre os profissionais e alunos que conduziram as práticas e os participantes.

A princípio, observou-se uma concentração de práticas educativas centradas na dimensão nutricional dos alimentos. Embora a DF seja uma doença que implique necessidades alimentares especiais, deve ser preconizada a diversidade alimentar, uma vez que nenhum alimento ou grupo de alimento sozinho é capaz de atender às necessidades do organismo. ${ }^{31}$ Da mesma forma, deve-se levar em conta que a alimentação apresenta múltiplas dimensões, para além do aspecto nutricional, que fazem com que as práticas alimentares sejam profundamente influenciadas por determinantes individuais e coletivos. ${ }^{35}$

Quando a EAN aborda o alimento em suas múltiplas dimensões, ela se aproxima da vida real das pessoas e permite o estabelecimento de vínculos, entre o processo pedagógico e as diferentes realidades e necessidades locais e familiares. Da mesma forma, usar a culinária como estratégia nessas ações permite que as recomendações para uma alimentação saudável possam ser incorporadas de maneira concreta cotidiano da vida. ${ }^{36}$

Outras limitações da experiência foram o desafio da adoção de estratégias metodológicas específicas para os diferentes ciclos de vida e a não participação de outras categorias profissionais nas ações.

As estratégias metodológicas utilizadas em EAN devem ser apropriadas para as faixas etárias, com temas de interesse para o grupo em questão e pautados nos recursos físicos e humanos, para o alcance dos objetivos propostos. Em relação à distribuição das faixas etárias, a composição dos grupos de sala de espera era mista, por isso as escolhas de estratégias foram mais abrangentes e mescladas. Isso permitiu identificar as estratégias mais adequadas para diferentes ciclos de vida.

O fato de os adultos participarem mais quando houve a presença dos alimentos concorda com as premissas da pedagogia, em que a experimentação desperta o interesse dos participantes, aumenta sua motivação e, por utilizar os sentidos do corpo, torna o processo de construção do conhecimento mais efetivo. As pessoas não se alimentam de nutrientes, mas de alimentos e preparações escolhidas e combinadas de maneira particular, com cheiro, cor, temperatura, textura e sabor. Alimentam-se também de seus significados e dos aspectos simbólicos. ${ }^{36}$ Nos processos de EAN, trabalhar com a comida aproxima as pessoas e, como já se discutiu, permite pensar as soluções dos obstáculos encontrados a partir do contexto de vida das pessoas. Isto refletiu num maior envolvimento das pessoas nas práticas que utilizavam alimentos. 
Com vistas à atenção integral a este grupo, o diálogo também deve estar presente entre os profissionais de saúde, com desenvolvimento de ações multiprofissionais. A alimentação é uma prática social e o ato de comer vai muito além da satisfação das necessidades biológicas. Assim, para que a EAN possa abarcar toda a complexidade da alimentação, é necessário que diferentes profissionais estejam envolvidos nas ações, não apenas o nutricionista, e que as ações tenham caráter permanente e transdisciplinar. ${ }^{35}$ Entretanto, na experiência apresentada só havia o olhar da Nutrição. Provavelmente, por ser relativamente recente a inserção do nutricionista nesta área de tratamento dos pacientes hematológicos, isto pode ter colaborado para uma atuação isolada.

O fato de ter sido utilizado o espaço de sala de espera trouxe limitações à proposta. A sala de espera é um território dinâmico, público, onde as pessoas se movimentam e aguardam atendimento. ${ }^{37}$ Esse dinamismo pode dificultar a formação de vínculos e o processo de construção compartilhada do conhecimento. Apesar disso, é um espaço frequentemente utilizado pelos profissionais de saúde para promoção de educação em saúde, por permitir a reunião das pessoas inativas, o que aumenta a chance de sua participação.

Neste sentido, apesar das limitações, grupos de sala de espera podem funcionar como um espaço em que as práticas de educação em saúde e, em última análise, a promoção da saúde, sejam maximizadas ${ }^{38}$ Pode-se considerar que as ações realizadas com os grupos de salas de espera foram viáveis e permitiram o exercício da escuta e o diálogo entre nutricionistas e os usuários.

Outro achado que fortaleceu a noção da EAN como uma ferramenta fundamental para promoção de uma vida saudável para pessoas com DF foram as divergências entre as recomendações atuais e o conhecimento dos participantes sobre especificidades alimentares da DF. Isto pode ser decorrente da discordância nas condutas dos profissionais de saúde sobre as orientações para alimentação adequada e saudável. É consenso que a DF afeta os requerimentos de alguns nutrientes, implicando prognóstico da doença, o que precisa ser exaustivamente difundido com o intuito de promover e garantir o acesso à informação a respeito das necessidades nutricionais neste grupo, aliado à noção já discutida de que a alimentação deve ser diversificada.

Nos grupos, observou-se a necessidade de que as práticas educativas em saúde voltadas a pessoas com DF fossem capazes de fomentar a construção de conhecimento compartilhado, propiciando maior autonomia para escolhas mais adequadas em relação às fontes alimentares de nutrientes sabidamente deficientes nesses indivíduos.

Embora ainda frequente nas orientações de alguns profissionais, não há evidências científicas que sustentem a conduta restritiva diária de ferro e o estímulo do consumo de alimentos inibidores da absorção de ferro nas grandes refeições. Observa-se que o quadro de sobrecarga de ferro ocorre predominantemente em pessoas em esquemas de transfusões crônicas. ${ }^{16}$ 
O que se tem claro é que os alimentos fontes de ferro não devem ser excluídos da alimentação das pessoas com doença falciforme. ${ }^{32}$ Devem ser investigadas a presença e a frequência das terapias de transfusões, assim como o uso de medicamentos quelantes de ferro, a fim de diagnosticar o estado de ferro corporal. Mesmo na ocorrência de sobrecarga de ferro, devem ser desencorajadas dietas muito restritas de seus alimentos fontes ou de uso de condutas que reduzam sua biodisponibilidade, como a combinação de alimentos fontes de ferro com produtos lácteos, visto que os principais alimentos fontes são os alimentos proteicos de origem animal, que também são importantes fontes de proteínas, de zinco e de vitamina B12. ${ }^{39}$

Em contraponto, a deficiência de ferro pode estar presente em alguns indivíduos com DF, em razão de flebotomias repetidas, transfusões excessivas ou hematúria secundária à necrose papilar renal, ${ }^{40}$ além de consumo insuficiente de alimentos fontes.

Cabe também a reflexão sobre a rotina da orientação sobre a alimentação na atenção a este grupo. Por ser uma doença crônica, as pessoas com DF têm inúmeros encontros com diversos profissionais de saúde ao longo de sua vida, o que deveria constituir um espaço privilegiado para promoção da saúde.

A promoção da alimentação adequada e saudável para as pessoas com doença falciforme deve ser parte integrante do cuidado, seja no âmbito individual ou coletivo, em todos os níveis de assistência, visto o papel fundamental da alimentação adequada no curso da doença.

As ações de promoção de saúde podem ser, por exemplo, medidas de incentivo a adoção de hábitos alimentares saudáveis, de apoio para que os indivíduos informados e motivados possam adquiri estes hábitos, ou de proteção a fatores e situações que estimulem a práticas não saudáveis. ${ }^{41}$ As práticas educativas para a PAAS são exemplos de medidas de incentivo, cujo propósito é difundir informações e motivar os indivíduos. Considerando-se a alimentação como um processo social, ela é influenciada pelo ambiente em que a vida acontece. Sendo assim, nessas práticas deve-se refletir também sobre a necessidade de medidas que envolvam outras vertentes de promoção da saúde. ${ }^{42}$

O cenário social da DF é especialmente importante para a definição das estratégias voltadas à promoção da saúde e da alimentação saudável, implicando a necessidade de intervenções mais estruturais e abrangentes. A alimentação é condicionada por diversos fatores, desde os mais ligados ao indivíduo - neste caso, a própria DF implica necessidades alimentares especiais - até os fatores coletivos, ligados ao ambiente em que essas pessoas vivem. Neste sentido, para as ações de promoção da alimentação adequada e saudável para este grupo, não se pode desconsiderar as profundas iniquidades históricas de saúde da população negra, que refletem, por exemplo, na relação entre as desigualdades raciais e maiores prevalências de IA. 


\section{Considerações finais}

O relato apresentou algumas limitações metodológicas, como a não aplicação do questionário de identificação prévia dos usuários em todas as atividades realizadas e a ausência de avaliação em algumas práticas, uma vez que esta só passou a ocorrer a partir de 2011.

A experiência apresentada trouxe reflexões importantes sobre a necessidade de a educação alimentar e nutricional ser uma ferramenta comum aos profissionais de saúde, com estímulo à adoção de ações multiprofissionais, em toda a rede de assistência as pessoas com a doença falciforme. Com este propósito, houve a inserção da psicologia nas atividades de sala de espera desenvolvidas. Outro desdobramento da experiência relatada foi a ampliação pelo NUTRIFAL, a partir da parceria com as associações de pessoas com DF, de ações de EAN, implementando grupos com as famílias e/ou cuidadores de crianças com esta doença. As ações são realizadas em um equipamento de referência de atenção a este grupo. Os encontros ocorrem em locais fechados, com agendamento, e estão inseridos nos cronogramas de reuniões das organizações, constituindo um espaço oportuno para a construção compartilhada do conhecimento.

A elaboração deste relato contribuiu para a mudança do olhar do grupo, para além da dimensão biológica do alimento, resultando em mudanças no foco das práticas educativas.

As ações de promoção da alimentação adequada e saudável do NUTRIFAL abarcam ainda, em maior escala, a elaboração de materiais educativos para a população e profissionais de saúde ligados à temática, além de encontros com as nutricionistas das redes básicas de saúde estadual e municipais, com o intuito de discutir o papel da alimentação na DF e fomentar a integração das necessidades alimentares deste grupo às demandas da atenção nutricional. Neste sentido, as reflexões contribuem para qualificação destas ações desenvolvidas.

Por fim, a oportunidade deste relato reforça que deve ser exaustivamente promovido o diálogo entre pessoas com DF, familiares e profissionais que lidam com a doença, com vistas à promoção da alimentação adequada e saudável. Quebrar a hegemonia existente entre os profissionais que permita a inter-relação e, consequentemente, rompa as barreiras do saber deve ser um dos objetivos maior da práxis dos profissionais de saúde e afins a esta temática.

\section{Agradecimentos}

As autoras agradecem ao Ministério da Saúde, na pessoa da Dra Joice Aragão, pelo financiamento do Centro de Referência de Nutrição à Pessoa com Doença Falciforme (NUTRIFAL), e ao Coordenador do Programa de Doença Falciforme no Estado do Rio de Janeiro, Dr. Paulo Ivo Araujo, pelo apoio às atividades desenvolvidas pelo NUTRIFAL. 


\section{Referências}

1. Brasil. Manual de diagnóstico e tratamento de doenças falciformes. Brasília: ANVISA; 2002.142 p.

2. Loureiro MM, Rozenfeld S. Epidemiologia de internações por doença falciforme hospitalares no Brasil. Cadernos de Saúde Pública 2005; 39(6):943-9.

3. Naoum PC. Eritrócitos e interferências ambientais sobre a anemia falciforme. Revista Brasileira de Hematologia 2000; 22(1):05-22.

4. Ramalho AS, Magna 1A, Paiva-e-Silva RB. A Portaria no 822/01 do Ministério da Saúde e as peculiaridades das hemoglobinopatias em saúde pública no Brasil. Caderno de Saúde Pública 2003; 19(4):1195-1199.

5. Máximo CA. Política de atenção integral à pessoa com doença falciforme no estado do Rio de Janeiro e os desafios da descentralização [dissertação]. Rio de Janeiro: Escola Nacional de Saúde Pública, Fundação Oswaldo Cruz; 2009.

6. Panepinto JA, Hoffmann RG, Pajewski NM. A psychometric evaluation of the PedsQL family impact module in parents of children with sickle cell disease. Health and Quality of Life Outcomes 2009; 32(7):2-11.

7. Mcclish D, Penberthy LT, Bovbjerg VE, Roberts, JD, Aisiku IP, Levenson, JL, et al. Health related quality of life in sickle cell patients: the PiSCES project. Health Quality Life Outcomes 2005; 3(50):01-07.

8. Palermo TM, Schwartz L, Drotar D, McGowan, K. Parental report of health-related quality of life in children with sickle cell disease. Journal of behavioral medicine 2002; 25(3):269-83.

9. Santoro MS. Rede pública de hematologia e hemoterapia: o mapa do atendimento do paciente portador de doença falciforme no estado do Rio de Janeiro [dissertação]. Rio de janeiro: Universidade Estácio de Sá; 2010.

10. Kikuchi BA. Cuidados de enfermagem na doença falciforme nos serviços de atenção primária. Revista Brasileira de Hematologia 2007; 29(3):331-38.

11. Lobo C, Marra VN, Silva RMG. Episódios dolorosos na doença falciforme. Revista Brasileira de Hematologia 2007; 29(3):247-258.

12. Fowler KT, Williams R, Mitchell CO, Levy MC, Pope LF, Smeltzer MP, et al. Dietary water and sodium intake of children and adolescents with sickle cell anemia. Journal of Pediatriac Hematology Oncology 2010; 5(32):350-353.

13. Reid M. Nutrition and sickle cell disease. Compets Rendus Biologies 2013; 336:159-163.

14. Williams R, Olivi S, Li CS, Storm M, Cremer L, Mackert P, et al. Oral glutamine supplementation decreases resting energy expenditure in children and adolescents with sickle cell anemia. Journal Pediatric Hematolology Oncology 2004; 26(10):619-625.

15. Mataratzis PSR, Accioly E, Padilha PC. As deficiências de micronutrientes em crianças e adolescentes portadores de anemia falciforme: uma revisão sistemática. Revista Brasileira de Hematologia 2010; 32(3):247-256. 
16. Wood JC, Tyszka JM, Carson S, Nelson MD, Coates TD. Myocardial iron loading in transfusiondependent thalassemia and sickle cell disease. Blood 2004; 103(5):1934-1936.

17. Brasil. Ministério da Saúde. Política nacional de saúde integral da população negra: uma política para o SUS. 2 ed. Brasília: Ministério da Saúde; 2013. 36 p.

18. Felix AA, Souza HM, Ribeiro SBF. Aspectos epidemiológicos e sociais da doença falciforme. Revista Brasileira de Hematologia 2010; 32(3):203-208.

19. Silva RBP, Ramalho AS, Cassorla RMS. Anemia falciforme como problema de saúde pública no Brasil. Cadernos de Saúde Pública 1993; 27(1):54-58.

20. Brasil. Conselho Nacional de Segurança Alimentar e Nutricional. Princípios e diretrizes de uma política de segurança alimentar e nutricional. Textos de referência da II Conferência Nacional de Segurança Alimentar e Nutricional. Brasília: Consea; 2004. 80 p.

21. Instituto Brasileiro de Geografia e Estatística. Diretoria de pesquisas. coordenação de trabalho e rendimento. Pesquisa nacional por amostra de domicílios - segurança alimentar 2004/2009. Rio de Janeiro: IBGE; 2010. 183 p.

22. Segall-Corrêa AM, Marín-León L, Panigassi G, Pérez-Escamilla R. Segurança alimentar no domicílio. In: Brasil. Pesquisa Nacional de Demografia e Saúde da Criança e da Mulher. PNDS 2006: dimensões do processo reprodutivo e da saúde da criança. Brasília: Ministério da Saúde; 2009. p. 231-348.

23. Hasanato R. Zinc and antioxidant vitamin deficiency in patients with severe sickle cell anemia. Annals of Saudi Medicine 2006; 26(1):17-21.

24. Brasil. Ministério da Saúde. Dialogando sobre o direito humano à alimentação adequada no contexto do SUS. Brasília: Ministério da Saúde; 2010. 72 p.

25. Mesa Brasil Sesc. Banco de alimentos e colheita urbana: aproveitamento integral dos alimentos. Rio de Janeiro: SESC/DN; 2003. p. 45.

26. Fasola F, Adedapo K, Anetor J, Kuti M. Total antioxidants status and some hematological values in sickle cell disease patients in steady state. Journal of the national medical association 2007; 99(8):891-894.

27. Verissimo MPA. Crescimento e desenvolvimento nas doenças falciformes. Revista Brasileira de Hematologia e Hemoterapia 2007; 29(3):271-274.

28. Nouraine M, Cheng K, Niu X, Moore-King E, Fadojutimi-Akinsi MF, Minniti CP, et al. Predictors of osteoclast activity in patients with sickle cell disease. Haematologica 2011; 96(8):1092-1098.

29. Di Nuzzo DVP, Fonseca SF. Anemia falciforme e infecções. Jornal de Pediatria 2004; 80(5):347-54.

30. Borel MJ, Buchowski MS, Turner EA, Peeler BB, Goldstein RE, Flakoll PJ. Alterations in basal nutrient metabolism increase resting energy expenditure in sickle cell disease. American Physiological Society 1998; (2 Pt. 1):E357-E364.

31. Brasil. Ministério da Saúde. Guia alimentar para a população brasileira: promovendo a alimentação saudável. Brasília: Ministério da Saúde; 2006. p. 210.

32. Viera MP, Lima IN, Petilik MEI. Abordagem ambulatorial do nutricionista em anemia hemolítica. Revista de Nutrição 1999; 12(1):103-113. 
33. Araujo PIC. O autocuidado na doença falciforme. Revista brasileira de hematologia e hemoterapia 2007; 29(3):239-246.

34. Freire P. Pedagogia da autonomia: saberes necessários à prática educativa. Rio de Janeiro: Paz e Terra; 1996.

35. Burity V, Franceschini T, Valente F, Recine E, Leão M, Carvalho MF. Direito humano à alimentação adequada no contexto da segurança alimentar e nutricional. Brasília: ABRANDH; 2010. p. 204.

36. Brasil. Ministério do Desenvolvimento Social e Combate à Fome. Marco de referência de educação alimentar e nutricional para as políticas públicas. Brasília: MDS; 2012. 68 p.

37. Teixeira ER, Veloso RC. O grupo em sala de espera: território de práticas e representações em saúde. Texto Contexto Enfermagem 2006; 15(2):320-5.

38. Rosa J, Barth PO, Germani ARM. A sala de espera no agir em saúde: espaço de educação e promoção à saúde. Perspectiva, Erechim 2011; 35(129):121-130.

39. Phillippi TS. Tabela de composição de alimentos: suporte para decisão nutricional. São Paulo: Coronário; 2002. p.135.

40. Stopler T, Weiner S. Tratamento clínico e nutricional para anemia. In: Mahan LK, Escott-Stump S, Raymond JL. Krause: alimentos, nutrição e dietoterapia. Rio de Janeiro: Elsevier; 2012. p. 725-739.

41. Brasil. Ministério da Saúde. Obesidade. Brasília: Ministério da Saúde; 2006. p. 108.

42. Rosa J, Barth PO, Germani A. A sala de espera no agir em saúde: espaço de educação e promoção à saúde. Perspectiva, Erechim 2011; 35(129):121-130.

Recebido: $15 / 4 / 2014$

Revisado: $29 / 5 / 2014$

Aprovado: 07/7/2014 